\title{
Increased cardiovascular risk markers in obesity are associated with body adiposity: Role of leptin
}

\author{
Javier Gómez-Ambrosi', Javier Salvador², Camilo Silva², Carlos Pastor³ ${ }^{3}$ Fernando Rotellar ${ }^{3}$, María J. Gil ${ }^{4}$, \\ Javier A. Cienfuegos ${ }^{3}$, Gema Frühbeck ${ }^{1,2}$ \\ 'Metabolic Research Laboratory, ${ }^{2}$ Department of Endocrinology, ${ }^{3}$ Department of Surgery and ${ }^{4}$ Department of Biochemistry; Clínica \\ Universitaria de Navarra, University of Navarra, Pamplona, Spain
}

\section{Summary}

Epidemiological studies have shown that obesity is associated with increased blood concentrations of proinflammatory factors and markers of endothelial dysfunction such as fibrinogen, C-reactive protein (CRP), and von Willebrand factor (vWF). We analyzed the association of these markers with percentage of body fat (BF), and the influence of leptin in a cross-sectional study of I,089 subjects (366 men) aged 44 (34-53) [median (interquartile range)] years, who were classified as obese or nonobese according to BF estimated by whole-body air displacement plethysmography. Obesity was defined as $B F \geq 25 \%$ in men and $\geq 35 \%$ in women. Compared with non-obese subjects (mean \pm SD), obese patients had higher concentrations of fibrinogen $(3 \mathrm{I} 2 \pm 78 \mathrm{vs} .342 \pm 8 \mathrm{I} \mathrm{mg} / \mathrm{dl}, P<0.00 \mathrm{I}), \mathrm{CRP}(0.4 \mathrm{I} \pm 0.75 \mathrm{vs} .0 .75$ $\pm 1.04 \mathrm{mg} / \mathrm{l}, P=0.014), \mathrm{vWF}(107 \pm 29 \mathrm{vs} .123 \pm 55 \%, P<0.00 \mathrm{I})$, and leptin ( $10.4 \pm 6.5$ vs. $37.5 \pm 26 . \mathrm{I} \mathrm{ng} / \mathrm{ml}, P<0.000 \mathrm{I})$. A positive correlation was observed between $\mathrm{BF}$ and fibrinogen $(r=$ $0.266 ; P<0.000 \mathrm{I}), \log C R P(r=0.409 ; P<0.000 \mathrm{I})$, and VWF $(r$ $=206 ; P<0.000 \mathrm{I})$. Leptin was correlated with fibrinogen $(r=$ $0.219, P<0.0001), \log C R P(r=0.339, P<0.0001)$, and vWF $(r$ $=0.124, P=0.002$ ), but the statistical significance was lost after including $\mathrm{BF}$ in adjusted-correlation and multivariate analysis, suggesting that they are not regulated by leptin per se. In conclusion, the obesity-associated increase in the circulating concentrations of fibrinogen, CRP, and vWF is highly associated to BF and apparently not determined by leptin.

\section{Keywords}

Obesity, adipose tissue, inflammation, leptin, insulin resistance

Thromb Haemost 2006; 95: 991-6

\section{Introduction}

The prevalence of obesity is increasing dramatically worldwide $(1,2)$. Obesity is an independent risk factor for cardiovascular disease (CVD) development being associated with increased morbidity and mortality. Obesity is defined medically as a state of increased adipose tissue mass of sufficient magnitude to produce adverse health consequences. A great effort has been made during the last years to elucidate how excess adiposity leads to CVD $(1,2)$.

In the past decade, it has become increasingly evident that adipose tissue represents an important determinant of a chronic, low-grade inflammatory state. In this sense, obesity is associated with an increase in circulating inflammatory markers, including fibrinogen, C-reactive protein (CRP), and von Willebrand factor (vWF), among others (1, 3-5). In addition, excess adiposity is accompanied by a clustering of metabolic alterations that can lead to CVD. The pathophysiological relevance of adipocytederived factors resides in the participation of these molecules beyond body weight balance in vascular homeostasis through effects on blood pressure, fibrinolysis, coagulation, angiogenesis, and immunity, among others. Adipokines have been shown to be implicated either directly or indirectly in the regulation of several processes that regulate the development of inflammation, atherogenesis, hypertension, insulin resistance and vascular remodelling (5). In this sense, leptin has been shown to play a role in inflammation (6) and has been suggested to be involved in CVD (7). However, it is difficult to discriminate whether the involve- 
ment of leptin in CVD is due to leptin itself (hyperleptinaemia) or to obesity-related leptin resistance (8-10).

In the present study, we assessed the relationship between adiposity and well-known cardiovascular risk factors, which are classical biomarkers of inflammation, thrombosis, and endothelial dysfunction associated with adverse cardiovascular outcomes. In addition, in order to assess whether the association between fibrinogen, CRP, and vWF, and body fat is influenced by leptin, we also investigated the relationship of these markers with the mentioned adipokine.

\section{Patients and methods}

\section{Patient selection and characteristics}

We conducted a cross-sectional analysis of 1,089 volunteers (366 males/723 females), aged 18 to 75 years and free of known cardiovascular disease. Participants in the study were recruited from healthy volunteers and patients attending the Endocrinology and Surgery Departments at the University Clinic of Navarra for weight loss. The experimental design was approved, from an ethical and scientific standpoint, by the Hospital's Ethical Committee responsible for research, and informed consent was obtained from all subjects.

\section{Anthropometric measurements}

Body weight was measured with a digital scale to the nearest 0.1 $\mathrm{kg}$, and height was determined to the nearest $0.1 \mathrm{~cm}$ with a Holtain stadiometer (Holtain Ltd., Crymych, UK). Body mass index

Table I: Characteristics of non-obese and obese patients.

\begin{tabular}{|c|c|c|c|}
\hline & $\begin{array}{l}\text { Non-obese } \\
(n=\mid 22)\end{array}$ & $\begin{array}{l}\text { Obese } \\
(n=967)\end{array}$ & $P$ value \\
\hline Sex (male/female) & $45 / 77$ & $321 / 646$ & 0.417 \\
\hline Age (years) & $40(30-5 I)$ & $45(35-54)$ & 0.017 \\
\hline Weight (kg) & $74.2 \pm 13.0$ & $102.4 \pm 23.8$ & $<0.0001$ \\
\hline $\mathrm{BMI}\left(\mathrm{kg} / \mathrm{m}^{2}\right)$ & $26.6 \pm 3.1$ & $37.4 \pm 7.5$ & $<0.0001$ \\
\hline Body fat (\%) & $26.2 \pm 6.6$ & $45.3 \pm 8.1$ & $<0.0001$ \\
\hline $\mathrm{SBP}(\mathrm{mm} \mathrm{Hg})$ & $107 \pm 12$ & $121 \pm 17$ & $<0.0001$ \\
\hline $\mathrm{DBP}(\mathrm{mm} \mathrm{Hg})$ & $66 \pm 8$ & $74 \pm 11$ & $<0.001$ \\
\hline Glucose (mg/dl) & $89 \pm 16$ & $98 \pm 25$ & $<0.001$ \\
\hline Insulin $(\mu \mathrm{U} / \mathrm{ml})$ & $6.8 \pm 3.8$ & $14.7 \pm 11.1$ & $<0.0001$ \\
\hline HOMA index & $1.52 \pm 0.91$ & $3.64 \pm 3.21$ & $<0.0001$ \\
\hline Triglycerides (mg/dl) & $91 \pm 51$ & $123 \pm 80$ & $<0.0001$ \\
\hline Cholesterol (mg/dl) & $167 \pm 37$ & $192 \pm 43$ & $<0.0001$ \\
\hline LDL cholesterol $(\mathrm{mg} / \mathrm{dl})$ & $101 \pm 31$ & $124 \pm 37$ & $<0.0001$ \\
\hline HDL cholesterol (mg/dl) & $47 \pm 12$ & $44 \pm 12$ & 0.002 \\
\hline Uric acid (mg/dl) & $4.5 \pm 1.3$ & $5.3 \pm 1.5$ & $<0.0001$ \\
\hline Leptin (ng/ml) & $8.3(6.0-14.3)$ & $30.5(18.9-49.0)$ & $<0.0001$ \\
\hline Fibrinogen (mg/dl) & $312 \pm 78$ & $342 \pm 81$ & $<0.001$ \\
\hline C-reactive protein $(\mathrm{mg} / \mathrm{l})$ & $0.17(0.08-0.48)$ & $0.50(0.20-0.90)$ & 0.014 \\
\hline von Willebrand factor (\%) & $107 \pm 29$ & $123 \pm 55$ & $<0.001$ \\
\hline
\end{tabular}

Data presented as mean $\pm S D$, except for age, leptin and CRP [median (interquartile range)]. Obesity was defined as $B F \geq 25 \%$ in men and $\geq 35 \%$ in women. $P$, non-obese vs. obese by unpaired Student's $t$ tests (except differences in gender distribution which was analyzed by $\mathrm{Chi}^{2}$-analysis). BMl: body mass index; SBP: systolic blood pressure; DBP: diastolic blood pressure; HOMA: homeostasis model assessment.
(BMI) was calculated as weight in $\mathrm{kg}$ divided by the square of height in meters. Body fat percentage (BF) was estimated by airdisplacement-plethysmography $\left(\right.$ Bod-Pod $^{\circledR}$, Life Measurements, Concord, CA, USA) (11). Obesity was defined as BF $\geq 25 \%$ in men and $\geq 35 \%$ in women (12). Blood pressure was measured after a five-minute rest in the semi-sitting position with a sphygmomanometer. Blood pressure was determined at least three times at the right upper arm, and the mean was used in the analyses.

\section{Blood analyses}

Blood was obtained by venipuncture after an overnight fast. Serum glucose was analyzed by an automated analyzer (Roche/ Hitachi Modular P800), with quantification being based on enzymatic colorimetric reactions. Serum insulin was measured by means of an enzymeamplified chemiluminescence assay (Immulite $^{\circledR}$, Diagnostic Products Corp., Los Angeles, CA, USA). The homeostasis model assessment (HOMA) score of insulin sensitivity was calculated with the formula: fasting serum insulin $(\mu \mathrm{U} / \mathrm{ml}) \mathrm{x}$ fasting plasma glucose $(\mathrm{mM}) / 22.5$ (13). Total cholesterol and triglyceride concentrations were determined by enzymatic spectrophotometric methods (Roche, Basel, Switzerland). HDL cholesterol was quantified by a colorimetric method in a Beckman Synchron ${ }^{\circledR}$ CX analyzer (Beckman Instruments, Ltd., Bucks, UK). LDL cholesterol was calculated by the Friedewald formula. Uric acid was measured by an enzymatic test (Roche) in an automated analyzer (Roche/Hitachi Modular P800).

Fibrinogen concentrations were determined according to the method of Clauss using a commercially available kit (Hemoliance ${ }^{\circledR}$, Instrumentation Laboratory, Barcelona, Spain). Highsensitivity CRP was measured using the Tina-quant ${ }^{\mathbb{B}}$ CRP (Latex) ultrasensitive assay (Roche). Measurement of vWF antigen was performed by a micro-latex immunoassay (Diagnostica Stago, Inc., Parsippany, NJ, USA). A standard curve was prepared with a universal reference (NISBC 91/666) and the results were expressed as percentage of the standard. Intra- and interassay coefficients of variation were $4.0 \%$ and $8.0 \%$, respectively. Leptin was measured by a double-antibody RIA method (Linco Research Inc., St. Charles, MO, USA). Intra- and inter-assay coefficients of variation were $5.0 \%$ and $4.5 \%$, respectively.

\section{Statistical analyses}

Data are presented as mean \pm standard deviation (SD) except for age, leptin and CRP, which are presented as median (interquartile range). Sex distribution between the non-obese and obese groups were assessed with the use of $\mathrm{Chi}^{2}$-analysis. Differences between groups were analysed by two-tailed unpaired Student's t-tests. Leptin and CRP concentrations were logarithmically transformed because of their non-normal distribution. We used crude and partial Pearson's correlation coefficients to test the statistical relations between variables. Direct multivariate linear regression analyses were conducted for the dependent variables fibrinogen, $\mathrm{CRP}$, and $\mathrm{vWF}$, including the parameters which showed a significant correlation with these markers as independent variables. The calculations were performed using the SPSS version 11.0 statistical package (SPSS, Chicago, IL, USA). A $P$ value lower than 0.05 was considered statistically significant. 


\section{Results}

Table 1 summarises the clinical characteristics of the study participants classified on the basis of BF. No differences $(P=0.417)$ in sex distribution between the non-obese and obese groups were observed. Body fat percentage was $73 \%$ higher in the obese group. As expected, a gender dimorphism in $\mathrm{BF}$ in the whole sample was observed (males vs. females, $37.0 \pm 0.5$ vs. $46.3 \pm$ $0.3 \% ; P<0.0001)$. Obese patients showed higher systolic and diastolic blood pressures, increased glycaemia and insulinaemia, and higher concentrations of triglycerides, total and LDL cholesterol and uric acid, as well as decreased HDL cholesterol levels. Obese subjects also showed significantly increased concentrations of fibrinogen $(P<0.001), \mathrm{CRP}(P=0.014)$ and $\mathrm{vWF}(P$ $<0.001)$.

As expected, obese subjects had significantly higher circulating concentrations of leptin. Leptin levels showed a close association with $\mathrm{BF}$ (Fig. 1), being higher in women than in men (males vs. females, $23.9 \pm 1.1$ vs. $40.1 \pm 1.2 \mathrm{ng} / \mathrm{ml} ; P<0.0001$ ), which correlates with the gender dimorphism observed in BF. Logarithmically transformed leptin showed a stronger correlation with $\mathrm{BF}$ in the whole sample $(r=0.738, P<0.0001)$, or separately analysing men $(r=0.750, P<0.0001)$ or women $(r=0.668, P<$ 0.0001).

Body fat was strongly correlated $(P<0.0001)$ with fibrinogen, CRP and vWF as illustrated in Table 2 and Figure 2. Fibrinogen concentrations were also significantly associated with sex (male $=1$; female $=2$ ), BMI, HOMA and leptin, showing a borderline relation with waist circumference $(r=0.084, P=0.074)$. The logarithmic values of CRP were significantly associated with BMI, waist circumference, HOMA, triglycerides, total and HDL cholesterol, uric acid, as well as leptin, showing a borderline relation with WHR $(r=0.099, P=0.091)$. vWF concentrations were significantly associated with age, BMI, waist circumference, HOMA, total cholesterol, uric acid, and leptin, showing a borderline relation with HDL cholesterol $(r=0.069, P=0.081)$.

As mentioned above, logleptin was strongly related to fibrinogen $(r=0.219, P<0.0001), \log \mathrm{CRP}(r=0.339, P<0.0001)$, and $\mathrm{vWF}(r=0.124, P=0.002)$ [men: fibrinogen $(r=0.290, P<$ $0.0001), \log \mathrm{CRP}(r=0.313, P<0.0001)$, and vWF $(r=0.123, P$ $=0.073)$; women: fibrinogen $(r=0.129, P=0.003), \log \mathrm{CRP}(r=$ $0.383, P<0.0001)$, and vWF $(r=0.124, P=0.014)]$. However, after stratification for obesity the logleptin association with $\log \mathrm{CRP}$ and $\mathrm{vWF}$ was lost in the non-obese group [non-obese: fibrinogen $(r=0.306, P=0.005), \log \mathrm{CRP}(r=-0.117, P=$ $0.462)$, and $\mathrm{vWF}(r=-0.227, P=0.126)$; obese: fibrinogen $(r=$ $0.159, P<0.0001), \log \mathrm{CRP}(r=0.318, P<0.0001)$, and vWF $(r$ $=0.109, P=0.010)]$. Given the fact that leptin is highly correlated to BF (Fig. 1), we carried out the same correlation analysis adjusting for $\mathrm{BF}$ in order to discard that the observed associations with leptin were not merely reflecting the correlation between the cardiovascular risk factors studied and adiposity. We found that the statistical significance was lost in partial correlation analyses after adjusting for BF [fibrinogen $(r=0.035, P$ $=0.327), \log \mathrm{CRP}(r=0.061, P=0.149)$, and $\mathrm{vWF}(r=-0.043$, $P=0.294)$ ]. In order to better characterise the relationships between leptin and the cardiovascular risk factors studied, and to find out which variables better predict them, we performed

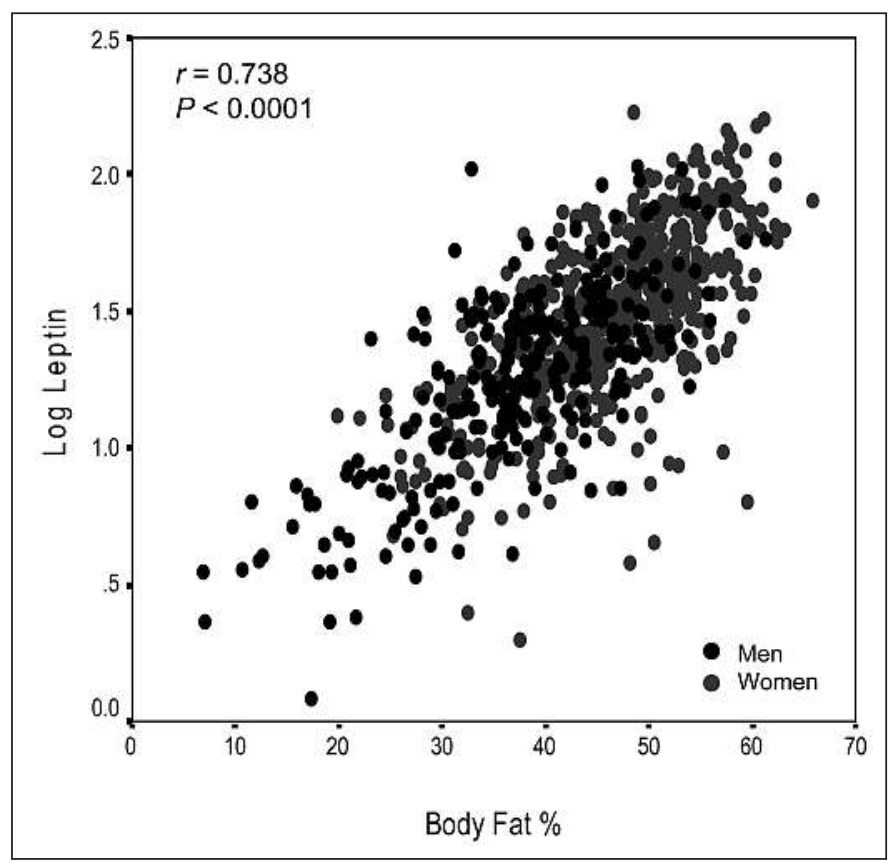

Figure I: Scatter diagram showing the highly significant positive correlations found between body fat percentage and the circulating concentrations of leptin. Pearson's correlation coefficient and $P$ value are indicated. The black circles represent men and the grey symbols women.

multivariate linear regression analyses. Since both BMI and BF are indicators of total body fat amount, we only included BF in the multivariate analysis, given the fact that two of the three dependent variables were more related to $\mathrm{BF}$ than to $\mathrm{BMI}$ and that $\mathrm{BF}$ is a better indicator of obesity (14). BF was a significant independent determinant of fibrinogen concentrations while HOMA had a marginal influence. However, the model only ex-

Table 2: Pearson correlation coefficients between anthropometric and biochemical variables, and fibrinogen, CRP, and vWF in the total sample of non-obese and obese subjects.

\begin{tabular}{|l|l|l|l|l|l|l}
\hline \multirow{2}{*}{} & \multicolumn{2}{|c|}{ Fibrinogen } & \multicolumn{2}{c|}{ logCRP } & \multicolumn{2}{c}{ vWF } \\
\cline { 2 - 7 } & $\boldsymbol{r}$ & $\boldsymbol{P}$ & $\boldsymbol{r}$ & $\boldsymbol{P}$ & $\boldsymbol{r}$ & P \\
\hline Sex & 0.151 & $* * *$ & 0.000 & NS & 0.035 & NS \\
\hline Age & 0.046 & NS & -0.054 & NS & 0.278 & $* * *$ \\
\hline Body fat \% & 0.266 & $* * *$ & 0.409 & $* * *$ & 0.206 & $* * *$ \\
\hline BMI & 0.161 & $* * *$ & 0.480 & $* * *$ & 0.194 & $* * *$ \\
\hline Waist & 0.084 & NS & 0.416 & $* * *$ & 0.139 & $*$ \\
\hline WHR & -0.069 & NS & 0.099 & NS & 0.025 & NS \\
\hline HOMA & 0.098 & $* *$ & 0.236 & $* * *$ & 0.164 & $* * *$ \\
\hline Triglycerides & -0.011 & NS & 0.109 & $* *$ & 0.032 & NS \\
\hline Cholesterol & 0.016 & NS & 0.116 & $* *$ & 0.099 & $*$ \\
\hline HDL cholesterol & 0.113 & NS & -0.157 & $* * *$ & 0.069 & NS \\
\hline Uric acid & 0.002 & NS & 0.225 & $* * *$ & 0.127 & $* *$ \\
\hline logLeptin & 0.219 & $* * *$ & 0.339 & $* * *$ & 0.124 & $* *$ \\
\hline
\end{tabular}

CRP: C-reactive protein; vWF: von Willebrand factor; BMI: body mass index; WHR: waist to hip ratio; HOMA: homeostasis model assessment. For correlation with sex: male $=I$; female $=2$. NS, non significant; $* P<0.05, * * P<0.01$, *** $P<0.001$ 


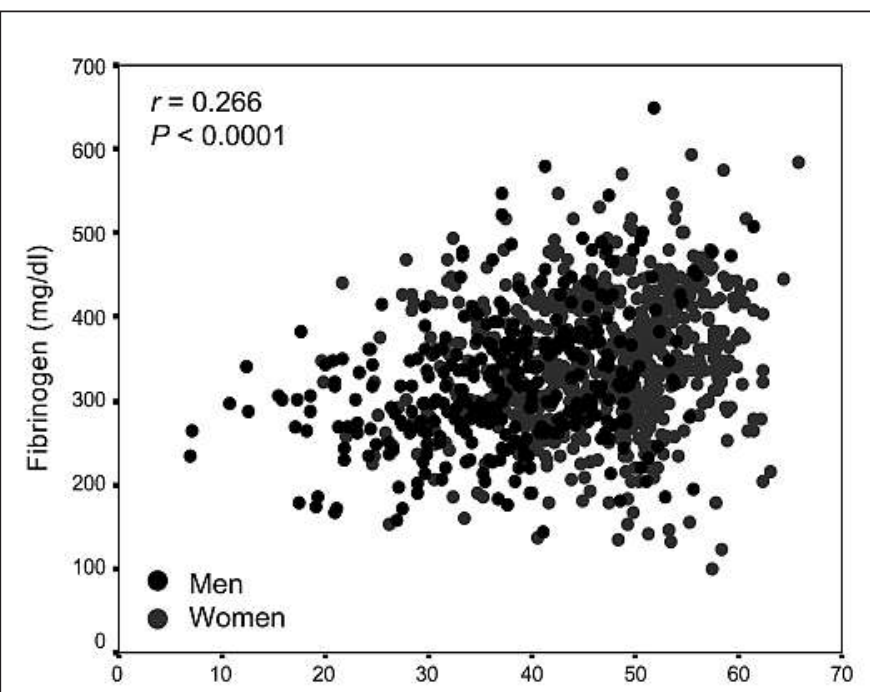

A)

Body Fat $\%$

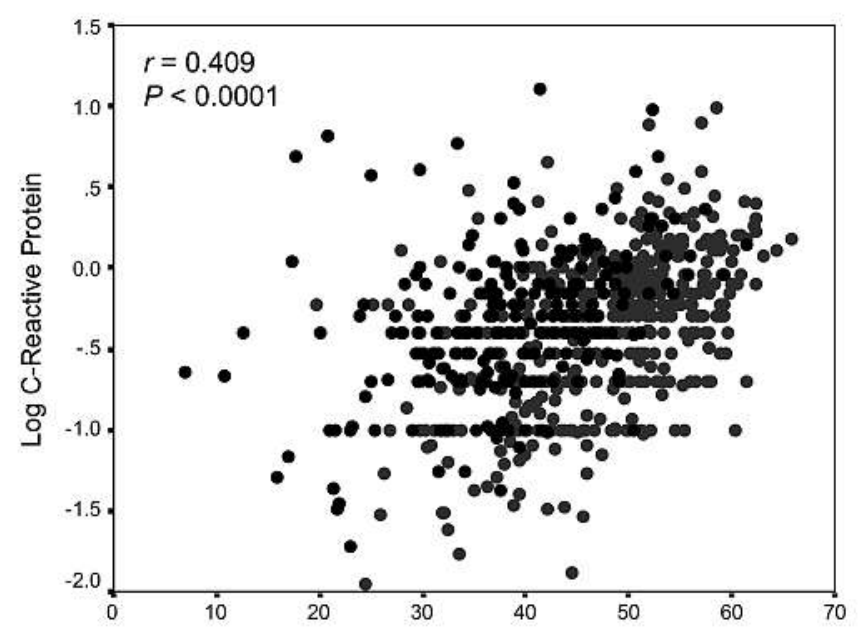

B)

Body Fat \%

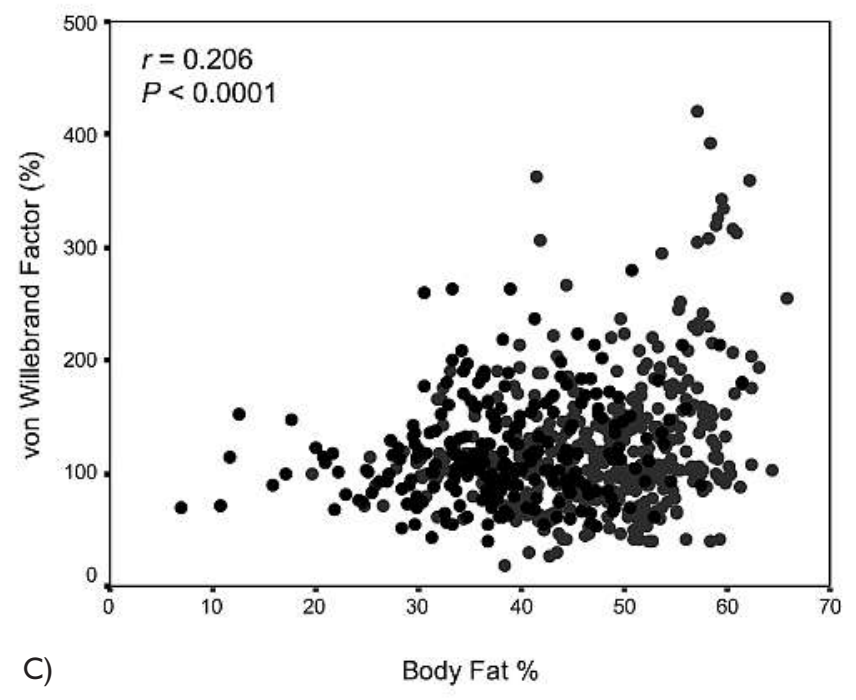

Table 3: Multiple regression analysis with fibrinogen, logCRP, and $v W F$ as dependent variables.

\begin{tabular}{|c|c|c|c|c|c|c|}
\hline & \multirow{2}{*}{\multicolumn{2}{|c|}{$\begin{array}{c}\text { Fibrinogen } \\
\begin{array}{c}r^{2}=0.076 \\
(P<0.0001)\end{array}\end{array}$}} & \multirow{2}{*}{\multicolumn{2}{|c|}{$\begin{array}{c}\log C R P \\
r^{2}=0.237 \\
(P<0.0001)\end{array}$}} & \multirow{2}{*}{\multicolumn{2}{|c|}{$\begin{array}{c}\text { vWF } \\
r^{2}=0.140 \\
(P<0.0001)\end{array}$}} \\
\hline & & & & & & \\
\hline & $\beta$ & $P$ & $\beta$ & $P$ & $\beta$ & $P$ \\
\hline Sex & 0.061 & 0.134 & & & & \\
\hline Age & & & & & 0.271 & $<0.0001$ \\
\hline Body Fat \% & 0.201 & $<0.001$ & 0.308 & $<0.001$ & 0.258 & 0.004 \\
\hline Waist & & & 0.134 & 0.124 & -0.117 & 0.197 \\
\hline HOMA & 0.061 & 0.108 & 0.059 & 0.361 & 0.121 & 0.074 \\
\hline Triglycerides & & & -0.006 & 0.928 & & \\
\hline Cholesterol & & & 0.031 & 0.638 & -0.052 & 0.404 \\
\hline HDL cholesterol & & & -0.093 & 0.151 & & \\
\hline Uric acid & & & 0.089 & 0.172 & 0.136 & 0.055 \\
\hline logLeptin & 0.036 & 0.494 & 0.013 & 0.872 & -0.032 & 0.713 \\
\hline
\end{tabular}

plained $8 \%$ of the variability of fibrinogen levels. The only significant independent determinant of CRP was BF, explaining $24 \%$ of its levels. Age and BF were significant independent determinants of vWF concentrations, while uric acid levels had a borderline influence $(\beta=0.136, P=0.055)$ (Table 3$)$. Age was the factor with more influence in the model with this latter explaining $14 \%$ of variability. In none of the models, leptin emerged as a significant predictor of the dependent variable analysed.

\section{Discussion}

Fibrinogen, CRP, and vWF, well known markers of inflammation and endothelial damage/dysfunction (15), were increased in the obese patients included in our study, which is in agreement with previous studies $(1,3,16-18)$. A positive association was found between these markers and BF, which in the case of fibrinogen and $\mathrm{vWF}$ was higher than the correlation observed with BMI $(17,19)$. Despite its wide use, BMI does not provide an accurate measure of body composition (14). In this context, more precise indicators need to be incorporated in the clinical diagnosis of obesity in order to better estimate the cardiovascular-related risk (20).

Although our study describes a marked correlation of fibrinogen, CRP, and vWF with BF, since it is a cross-sectional observation it does not provide insight into the nature of this association. A plausible underlying mechanism explaining the correlation between $\mathrm{BF}$ and CVD markers depends on the secretory

Figure 2: Scatter diagrams showing the highly significant positive correlations found between body fat percentage and the circulating concentrations of fibrinogen (A), logC-reactive protein (B), and von Willebrand factor (C). Pearson's correlation coefficients and $P$ values are indicated. The black circles represent men and the grey symbols women. After stratification by sex, men: fibrinogen $(r=$ $0.34 \mathrm{I}, P<0.000 \mathrm{I}), \log \mathrm{CRP}(r=0.378, P<0.000 \mathrm{I})$, and vWF $(r=0.178$, $P=0.005)$; women: fibrinogen $(r=0.159, P<0.0001)$, logCRP $(r=$ $0.508, P<0.000 \mathrm{I})$, and $\mathrm{VWF}(r=0.239, P<0.000 \mathrm{I})$. 
nature of adipose tissue, whereby the secreted adipokines may induce the production of these factors in the liver (fibrinogen and $\mathrm{CRP}$ ) and/or the endothelium (vWF). In this sense, although the markers analysed were significantly correlated with leptin concentrations, the statistical significance was lost after adjusting for $\mathrm{BF}$, suggesting that they are not regulated by leptin per se. The lack of association of leptin and fibrinogen after adjusting for $\mathrm{BF}$ is in agreement with other authors $(8,21,22)$. Previous studies analysing the relationship between leptin and CRP are controversial $(23)$. Our group $(18,24)$ and others $(25)$ have previously described that the positive correlation between leptin and $\mathrm{CRP}$ is biased by BF. However, other authors have reported that this correlation is still detected after adjusting for BMI $(26,27)$ or that exogenous leptin administration has no effect in humans $(23,28)$ or slightly increases CRP $(29,30)$. Contrarily, further authors describe an inverse correlation between leptin and CRP in tuberculosis or rheumatoid arthritis patients $(31,32)$. In the present study, CRP was highly correlated with leptin, but the significance was lost after adjusting for BF, indicating that CRP levels are not determined by leptin. However, our data are in contrast to those reported recently by another group (33) who has suggested that the association between leptin and CRP is not influenced by BMI. The fact that they studied older people than those included in our study [76 (65-103) vs. 44 (34-53) years], and that they adjusted for BMI instead of BF, which is a closer determinant of leptin concentrations, could explain such discrepancies. In our hands, this association merely reflects the correlation between CRP and adiposity with leptin not directly influencing CRP concentrations. This observation is reinforced by the fact that the association between leptin and CRP is not detected in non-obese subjects. Finally, leptin was also highly correlated with $v W F$. However, opposed to the findings of Guagnano et al. (34), this association was lost after adjusting for BF, which is in accordance with the study of Chu et al. (8). Differences in sample size or the fact that the association in the study by Guagnano et al. was only evident after excluding non-obese women may underlie this discrepancy.

The potential regulation of fibrinogen, CRP and vWF by other adipokines such as adiponectin, IL-6, TNF- $\alpha$, and resistin $(35,36)$, or the in situ production of these risk factors by adipose tissue itself, as has been shown to take place for PAI-1 (37) or CRP $(36,38)$, should also be considered. In this sense, adipose tissue is considered a source of vasoactive factors affecting the physiology of the vasculature via a tight cross-talk of adipokines with endothelial and smooth muscle cells, and hence exerting a relevant impact on the cardiovascular system (39).

Increased BF is closely related to insulin resistance (40). Although the obese subjects participating in our study showed aver- age levels of glucose and insulin within the normal range, they exhibited increased insulin resistance as compared to the nonobese ones, as evidenced by the significantly increased HOMA scores. This increase in insulin resistance could also be influencing the increase in the CVD markers studied (41). In this sense, a strong association was observed between HOMA values and fibrinogen, CRP and vWF. However, it seems that the obesityassociated increase in CRP detected in our study was independent of insulin resistance as evidenced by the lack of association of this factor with HOMA after adjusting for BF. Fibrinogen and vWF concentrations were marginally influenced by HOMA after adjusting for BF, which seems to indicate that these markers could be somewhat influenced by insulin resistance. Our results are in agreement with previous findings $(18,41,42)$ indicating that insulin resistance may, by itself or as a consequence of an increased fat mass, induce endothelial dysfunction and inflammation. The association of $\mathrm{VWF}$ with age was strong and consistent with the literature $(43,44)$. Although age could be influencing the increased concentrations of vWF in obesity observed in our study, given that our obese sample was slightly older, the multivariate analysis showed that body fat is still a significant determinant of vWF after adjustment by age. Finally, another factor slightly affecting vWF levels was uric acid. The role of uric acid as a cardiovascular risk factor remains controversial (45). Our data indicates that uric acid levels are associated with vWF concentrations, which is concordant with the association of uric acid with endothelial dysfunction, evidenced by increased carotid intima-media thickness and aortic stiffness, recently described (46). However, whether uric acid has a causative role or is a mere marker of CVD requires further research.

In conclusion, our observations draw attention to the relevance of determining body composition to quantify the fat compartment, which ultimately is the tissue responsible for most obesity-related cardiovascular derangements. In addition, our study provides evidence of direct associations between adipose tissue stores and circulating concentrations of fibrinogen, CRP, and vWF that appear not to be influenced by leptin.

\section{Acknowledgements}

This study was funded by Instituto de Salud Carlos III, FIS RGTO G03/028 from the Ministerio de Sanidad y Consumo, Spain and by the Department of Health of the Gobierno de Navarra (48/2003 and 20/2005), Spain. We thank the members of the Nutrition Unit, for their technical support in body composition analysis, and Paula Oroz and Beatriz Ramírez for her help with the database.

\section{References}

1. Rosito GA, D'Agostino RB, Massaro J, et al. Association between obesity and a prothrombotic state: the Framingham Offspring Study. Thromb Haemost 2004; 91: 683-9.

2. Eckel RH, York DA, Rössner S, et al. Prevention Conference VII: Obesity, a worldwide epidemic related to heart disease and stroke: executive summary. Circulation 2004; 110: 2968-75.
3. Visser M, Bouter LM, McQuillan GM, et al. Elevated C-reactive protein levels in overweight and obese adults. JAMA 1999; 282: 2131-5.

4. McLaughlin T, Abbasi F, Lamendola C, et al. Differentiation between obesity and insulin resistance in the association with C-reactive protein. Circulation 2002; 106: 2908-12.
5. Frühbeck G. The adipose tissue as a source of vasoactive factors. Curr Med Chem - Cardiovasc Hematol Agents 2004; 2: 197-208.

6. La Cava A, Matarese G. The weight of leptin in immunity. Nat Rev Immunol 2004; 4: 371-9.

7. Matsuzawa Y. White adipose tissue and cardiovascular disease. Best Pract Res Clin Endocrinol Metab 2005; 19: 637-47. 
8. Chu N, Spiegelman D, Hotamisligil GS, et al. Plasma insulin, leptin, and soluble TNF receptor levels in relation to obesity-related atherogenic and thrombogenic cardiovascular disease risk factors among men. Atherosclerosis 2001; 157: 495-503.

9. Jin X, Fukuda N, Su J, et al. Effects of leptin on endothelial function with OB-Rb gene transfer in Zucker fatty rats. Atherosclerosis 2003; 169: 225-33.

10. Ren J. Leptin and hyperleptinemia - from friend to foe for cardiovascular function. J Endocrinol 2004; 181: 1-10.

11. Collins AL, Saunders S, McCarthy HD, et al. Within- and between-laboratory precision in the measurement of body volume using air displacement plethysmography and its effect on body composition assessment. Int J Obes Relat Metab Disord 2004; 28: 80-90.

12. Pi Sunyer FX. Obesity: criteria and classification. Proc Nutr Soc 2000; 59: 505-9.

13. Matthews DR, Hosker JP, Rudenski AS, et al. Homeostasis model assessment: insulin resistance and beta-cell function from fasting plasma glucose and insulin concentrations in man. Diabetologia 1985; 28 : 412-9.

14. Prentice AM, Jebb SA. Beyond body mass index. Obes Rev 2001; 2: 141-7.

15. Hansson GK. Inflammation, atherosclerosis, and coronary artery disease. N Engl J Med 2005; 352: 1685-95.

16. Blann AD, Bushell D, Davies A, et al. von Willebrand factor, the endothelium and obesity. Int J Obes Relat Metab Disord 1993; 17: 723-5.

17. Lemieux I, Pascot A, Prud'homme D, et al. Elevated C-reactive protein: another component of the atherothrombotic profile of abdominal obesity. Arterioscler Thromb Vasc Biol 2001; 21: 961-7.

18. Gómez-Ambrosi J, Salvador J, Páramo JA, et al. Involvement of leptin in the association between percentage of body fat and cardiovascular risk factors. Clin Biochem 2002; 35: 315-20.

19. Bo M, Raspo S, Morra F, et al. Body fat is the main predictor of fibrinogen levels in healthy non-obese men. Metabolism 2004; 53: 984-8.

20. Frühbeck G. Screening and interventions for obesity in adults. Ann Intern Med 2004; 141: 245-6.

21. Söderberg S, Olsson T, Eliasson M, et al. Plasma leptin levels are associated with abnormal fibrinolysis in men and postmenopausal women. J Intern Med 1999; 245: 533-43.

22. Skurk T, van Harmelen V, Lee YM, et al. Relationship between IL-6, leptin and adiponectin and variables of fibrinolysis in overweight and obese hypertensive patients. Horm Metab Res 2002; 34: 659-63.
23. Chan JL, Bullen J, Stoyneva V, et al. Recombinant methionyl human leptin administration to achieve high physiologic or pharmacologic leptin levels does not alter circulating inflammatory marker levels in humans with leptin sufficiency or excess. J Clin Endocrinol Metab 2005; 90: 1618-24.

24. Gómez-Ambrosi J, Salvador J, Silva C, et al. Leptin therapy does not affect inflammatory markers. J Clin Endocrinol Metab 2005; 18: 3803.

25. van Dielen FM, van't Veer C, Schols AM, et al. Increased leptin concentrations correlate with increased concentrations of inflammatory markers in morbidly obese individuals. Int J Obes Relat Metab Disord 2001; 25: 1759-66.

26. Kazumi T, Kawaguchi A, Hirano T, et al. C-reactive protein in young, apparently healthy men: associations with serum leptin, QTc interval, and high-density lipoprotein-cholesterol. Metabolism 2003; 52: 1113-6.

27. Shamsuzzaman AS, Winnicki M, Wolk R, et al. Independent association between plasma leptin and C-reactive protein in healthy humans. Circulation 2004; 109: 2181-5.

28. Hukshorn CJ, van Dielen FMH, Buurman WA, et al. The effect of pegylated recombinant human leptin (PEG-OB) on weight loss and inflammatory status in obese subjects. Int J Obes Relat Metab Disord 2002; 26: 504-9.

29. Hukshorn $\mathrm{CJ}$, Lindeman $\mathrm{JH}$, Toet $\mathrm{KH}$, et al. Leptin and the proinflammatory state associated with human obesity. J Clin Endocrinol Metab 2004; 89: $1773-8$.

30. Canavan B, Salem RO, Schurgin S, et al. Effects of physiological leptin administration on markers of inflammation, platelet activation, and platelet aggregation during caloric deprivation. J Clin Endocrinol Metab 2005; 90: 5779-85.

31. Popa C, Netea MG, Radstake TR, et al. Markers of inflammation are negatively correlated with serum leptin in rheumatoid arthritis. Ann Rheum Dis 2005; 64: $1195-8$.

32. van Crevel R, Karyadi E, Netea MG, et al. Decreased plasma leptin concentrations in tuberculosis patients are associated with wasting and inflammation. J Clin Endocrinol Metab 2002; 87: 758-63.

33. Ble A, Windham BG, Bandinelli S, et al. Relation of plasma leptin to C-reactive protein in older adults (from the Invecchiare nel Chianti study). Am J Cardiol 2005; 96: 991-5

34. Guagnano MT, Romano M, Falco A, et al. Leptin increase is associated with markers of the hemostatic system in obese healthy women. J Thromb Haemost 2003; 1 : 2330-4.
35. Engeli S, Feldpausch M, Gorzelniak K, et al. Association between adiponectin and mediators of inflammation in obese women. Diabetes 2003; 52: 942-7.

36. Ouchi N, Kihara S, Funahashi T, et al. Reciprocal association of C-reactive protein with adiponectin in blood stream and adipose tissue. Circulation 2003; 107 $671-4$

37. Shimomura I, Funahashi T, Takahashi M, et al. Enhanced expression of PAI-1 in visceral fat: possible contributor to vascular disease in obesity. Nat Med 1996; 2: 800-3.

38. Calabro P, Chang DW, Willerson JT, et al. Release of C-reactive protein in response to inflammatory cytokines by human adipocytes: linking obesity to vascular inflammation. J Am Coll Cardiol 2005; 46: 1112-3.

39. Yudkin JS, Eringa E, Stehouwer CD. „Vasocrine“ signalling from perivascular fat: a mechanism linking insulin resistance to vascular disease. Lancet 2005 365: 1817-20.

40. Arner P. The adipocyte in insulin resistance: key molecules and the impact of the thiazolidinediones Trends Endocrinol Metab 2003; 14: 137-45.

41. Meigs JB, Mittleman MA, Nathan DM, et al. Hyperinsulinemia, hyperglycemia, and impaired hemostasis: the Framingham Offspring Study. JAMA 2000; 283: 221-8.

42. Pradhan AD, Cook NR, Buring JE, et al. C-reactive protein is independently associated with fasting insulin in nondiabetic women. Arterioscler Thromb Vasc Biol 2003; 23: 650-5.

43. Conlan MG, Folsom AR, Finch A, et al. Associations of factor VIII and von Willebrand factor with age, race, sex, and risk factors for atherosclerosis. The Atherosclerosis Risk in Communities (ARIC) Study. Thromb Haemost 1993; 70: 380-5.

44. Whincup PH, Danesh J, Walker M, et al. von Willebrand factor and coronary heart disease: prospective study and meta-analysis. Eur Heart J 2002; 23 1764-70

45. Hayden MR, Tyagi SC. Uric acid: A new look at an old risk marker for cardiovascular disease, metabolic syndrome, and type 2 diabetes mellitus: The urate redox shuttle. Nutr Metab 2004; 1: 10.

46. Erdogan D, Gullu H, Caliskan M, et al. Relationship of serum uric acid to measures of endothelial function and atherosclerosis in healthy adults. Int J Clin Pract 2005; 59: 1276-82. 